\title{
高出力パルスレーザーで加速した微小飛翔体の 衝突による衝撃実験
}

\author{
関根 利守, 小林敬道, 吉田 正典*, 田中 和夫** \\ 科学技術庁無機材質研究所（干 305-0044 茨城県つくば市並木 1-1） \\ *工業技術院 物質工学工業技術研究所 († 305-8565 茨城県つくば市東 1-1) \\ **大阪大学レーザー核融合研究センター（５ 565-0871 大阪府吹田市山田丘 2-6）
}

\section{Impact Shock Experiments of Mini-Flyers Accelerated by High-Intensity Pulsed Lasers}

\author{
Toshimori SEKINE, Takamichi KOBAYASHI, Masatake YOSHIDA,* and Kazuo TANAKA** \\ National Institute for Research in Inorganic Materials, 1-1 Namiki, Tsukuba, Ibaraki 305-0044 \\ *National Institute of Materials and Chemical Research, 1-1 Higashi, Tsukuba, Ibaraki 305-8565 \\ **Institute of Laser Engineering, Osaka University, 2-6 Yamadaoka, Suita, Osaka 565-0871
}

(Received January 18, 1999)

\begin{abstract}
We have carried out impact experiment of $\mathrm{Al}$ mini-flyers, which have been accelerated by high intensity pulsed lasers to generate ultra-high, dynamic pressures. A laser intensity of about $50 \mathrm{TW} / \mathrm{cm}^{2}$ can achieve an impact velocity of $40 \mathrm{~km} / \mathrm{s}$, corresponding to a terapascal range of pressure. Laser-shock recovery experiments of $\mathrm{hBN}$ and $\mathrm{SiC}$ were investigated up to $650 \mathrm{GPa}$, and recovered samples were compared with previous results by conventional shock experiments. Analyses of recovered samples reveal some differences in the quenched phase, which may apparently be attributed to short durations of laser-shock compressions.
\end{abstract}

Key Words: Laser shock, High-pressure generation, Sample recovery, hBN, SiC

1.はじめに

最近のレーザー技術の進展は目ざましいものがある. 高密度パルス光の発生技術の進展に伴い, その高密度エネ ルギーを利用した超高圧力の発生は, 米国や仏国などで研 究が開始され1970年代に幾つかの基礎的な研究結果が発 表されている1-4).この高密度パルス光レーザーを用いて の超高圧力の発生は, 通常の方法では達成不可能な圧力領 域を目ざせる,くり返しが可能, 測定系における制御の容 易さ,などいくつかの点で従来の超高圧力発生技術とは大 きく異なる。また同時に試料サイズが，通常の衝撃波実 験注1)の $10^{-1} \sim 10^{-3}$ 倍程度になるために注意しなければなら ない点が生じる.

特に, 衝撃圧縮時間は従来の方法では数 $100 \mathrm{~ns} \sim$ 数 $\mu \mathrm{s}$ 程 度あるのに対して,レーザー衝撃波での持続時間は通常パ ルス幅程度になり,たかだか10nsであり1ns以下になること もあり得る。また試料サイズの点から発生できる衝撃波 の平面性が問題になり一次元近似ができなくなり,精度の 高いユゴニオ注2)測定等を行う際には測定系の時間分解能
とともに空間分解能を高めたり, 空間的に均一なレーザー 光の制御が必要となる。

パルスレーザーによる衝撃波の発生には, 直接レーザー 照射法と間接レーザー照射法の 2 法がある。前者は, レー ザー衝撃実験の初期から行われ現在も使用されている.

一方, 間接照射法には, X線を利用する衝撃波の発生法と微 小飛翔体衝突法に大別される。

直接レーザー照射法ではアブレーションで生じる臨界 電子密度を持つ層の役割が重要であり, この密度は $\lambda=$ $1.06 \mu \mathrm{m}$ の光に対して $10^{21}$ 個 $\mathrm{cm}^{-3}$ 位であり,これは常圧下で の理想気体の 1 ルの密度の $2 \sim 3$ 桁大きい值である。この 層は入射光が波長の長さ程度にわたって減衰する領域で ある。この層の前には急速に準安定的熱伝導帯が生じ る。この熱伝導体はアブレーション流として粒子加速を 行い衝撃波がたつ状態へと安定化する。一方, 臨界電子密 度層の背後には膨張プラズマが生じ, レーザー照射開始後 数100psには音速で膨張する準定常流が生じる。この衝撃

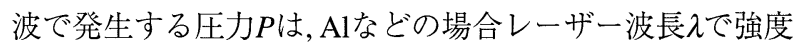

注1) 通常の衝撃波実験とは, 1 10cmサイズの試料を用いて, 爆薬法や衝撃銃での高速衝突法で得られる平面衝撃波を利用 した従来の衝撃圧縮を言う。

注2) ユゴニオとは, 衝撃波速度, 圧力, 密度, 体積などの状態パラメータをプロットした関係. 
$I$ の時 $P(\mathrm{GPa})=40\left(\frac{I\left(\mathrm{TW} / \mathrm{cm}^{2}\right)}{\lambda(\mu \mathrm{m})}\right)^{2 / 3}$ で近似される。典型的に は, 200GPa程度の圧力は発生可能である。しかし, 強度功 $10^{3} \mathrm{TW} / \mathrm{cm}^{2}$ 程度になると, 発生圧力は飽和し発生圧力の増 加が見込めなくなる.

間接レーザー照射法のうちX線を利用する方法は, $10^{3}$ $\mathrm{TW} / \mathrm{cm}^{2}$ を超えるようなX線を発生する強度以上のレー ザー光に対して有効であり, 電子温度が $T(\mathrm{keV})$ の時, 発生 圧力 $P(\mathrm{GPa})$ は次式で近似される。

$$
P(\mathrm{GPa})=2.3 \times 10^{5}(T(\mathrm{keV}))^{7 / 2}
$$

この方法は,大型レーザー施設で複数のビームを使用し, 状 態方程式等の決定に使用されている5,6).また, 微小飛翔体 加速法は, レーザー照射で金属䇴を加速し試料に超高速で 衝突させる衝撃波発生法である。この場合の発生圧力は, 衝突速度からインピーダンスマッチ法で算出できる。こ のような間接レーザー照射法は,試料の初期状態が既知で あるので状態方程式を決定する場合には特に重要な条件 になる。

本研究の目的は, 通常の衝撃実験より超高圧力の発生が 可能な衝撃圧縮実験で物質科学的に何ができるかを実験 的に検討することである．小論ではパルスレーザーエネ ルギーを利用した微小飛翔体の超高速衝突による衝撃波 の発生掠よびその衝撃波の物質科学への応用について述 べる．特に衝撃圧縮時間が通常の場合に比べて $10^{-2} \sim 10^{-4}$ 程度短時間になるので, この点について実験的な検討を加 える。

\section{2. 実験方法}

レーザーは阪大レーザー研の GM IIを使用した。パルス 幅500ps, 波長 $527 \mathrm{~nm}$, エネルギー5 30Jであり, 真空チャン バー中でビーム径 $1 \mathrm{~mm}$ に集光した。従って, 強度は打㧍よ そ10７0 TW $/ \mathrm{cm}^{2}$ の範囲となる。計算機シミュレーション によればこのような条件下で厚み $18 \mu \mathrm{m}$ Al薄膜にレーザー を照射するとAl薄膜は固体ではないが最初の厚みに対し

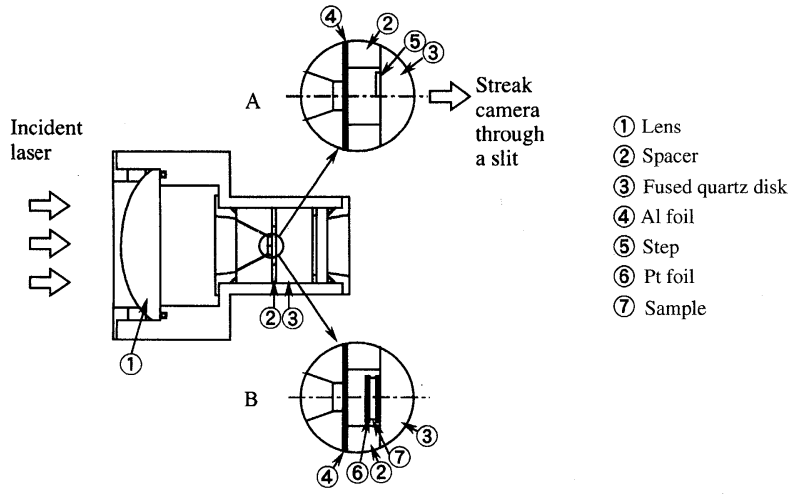

Fig.1 Illustration of target assembly used in the present study. Expansion A is for shots to measure the impact velocity and expansion $B$ is for recovery shots. て大半の部分が一体となって加速され約1ns以降はほぼ等 速度運動になる。従って, 距離約 $100 \mu \mathrm{m} の$ 飛行後はほほ等 速度と近似される。

本実験では，まず，このレーザーパルスによって加速さ れた微小飛翔体の速度を測定し, その衝突速度からイン ピーダンスマッチ法注3)で圧力の算出をする。使用した ターゲットはFig.1のようなものである。例えば10 $\mu \mathrm{m}$ 厚の $\mathrm{Al} 330 \mathrm{~km} / \mathrm{s}$ でAlに衝突したとすると発生圧力は, Alに対し て衝撃波速度 $U_{\mathrm{s}}$, 粒子速度 $u_{\mathrm{p}}$ の関係式

$$
U_{\mathrm{s}}=5.35+1.34 u_{\mathrm{p}}
$$

を使うと $P=1030 \mathrm{GPa}$ で圧縮持続時間は1ns程度になる，飛 翔体の速度の測定は,カバーガラス (厚さ約 $150 \mu \mathrm{m}$ )ででき たステップ(Fig.2)に $\mathrm{Al}$ 微小飛翔体が超高速で衝突した時 に発光する現象をストリークカメラで記録し,ステップ段 差の飛行時間(発光時間差)からその平均速度を算出寸る方 法を採用した7)

次に, 衝撃回収実験を通して, 試料回収を行う。衝撃回 収実験については, 通常の方法では特に100GPaを超える圧 力領域からの試料回収は困難をきわめるが, 総エネルギー の比較的小さいレーザー衝撃実験では, $1 \mathrm{TPa}(1000 \mathrm{GPa})$ 領

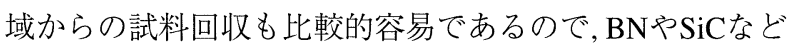
に関する回収実験を行った。試料はFig.1に示されたよう に白金箔にサンドウィッチされ衝撃波の破壊から保護さ れた。

出発原料の黑鉛状六方晶窒化ほう素 $(\mathrm{hBN})$ 粉末 ${ }^{8)}$ は, 厚 さ約 $0.3 \mu \mathrm{m}$ で粒径 $1 \sim 5 \mu \mathrm{m}$ の板状結晶粉末である. $\alpha-\mathrm{SiC}$ 粉

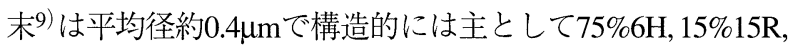
$6 \% 4 \mathrm{H}$ からなり, $\beta$ - $\mathrm{SiC}$ 粉末 ${ }^{9}$ は平均粒径 $0.03 \mu \mathrm{m}$ のほぼ球状 な粒子で構造的には3Cタイプからなる。これらの粉末を ピストンの間にはさみプレス成形し厚さ約 $50 \sim 100 \mu \mathrm{m}$ で $3 \mathrm{~mm} \times 3 \mathrm{~mm}$ 程度の大きさにし, 厚さ $10 \mu \mathrm{m}$ の白金箔でサン ドウィッチしたものをターゲットとして作製した.

\section{3. 実験結果}

Fig.2に示されているように, 衝突速度はストリーク写真 によるステップ段差での発光開始時間のずれ $t_{1}-t_{0}$ から平 均速度が得られた。これらの測定された平均速度はTable 1 にまとめられた。 $40 \mathrm{~km} / \mathrm{s}$ 程度までの衝突速度が得られ た。この時, 微小飛翔体は既に固体ではないが,一体となっ て飛翔しているものと考えられる。衝突によって発生す る圧力の推定には, この微小飛翔体の衝突前密度抢よび衝 撃波速度 $U_{\mathrm{s}}$ と粒子速度 $u_{\mathrm{p}}$ との関係式が必要であるが, 本実 験では大雑把であるが,使用したAl合金2024の密度2.70g/ $/ \mathrm{cm}^{3}$ および(1)式を使用した。これらの值を利用して,試料回収 実験の際の照射エネルギーの測定から飛翔体速度を推定 し,インピーダンスマッチ法により発生圧力の算出を行っ た。しかし上記の通り,飛翔体の衝突時の密度の不確かさ が主な理由としてこの算出圧力值は10２0\%程度大きく見

注3) インピーダンスマッチ法とは, 境界面を衝撃波が伝播する時にその境界面で圧力と粒子速度が連続であるとする，実 験的に良い近似であることが確認されている。 

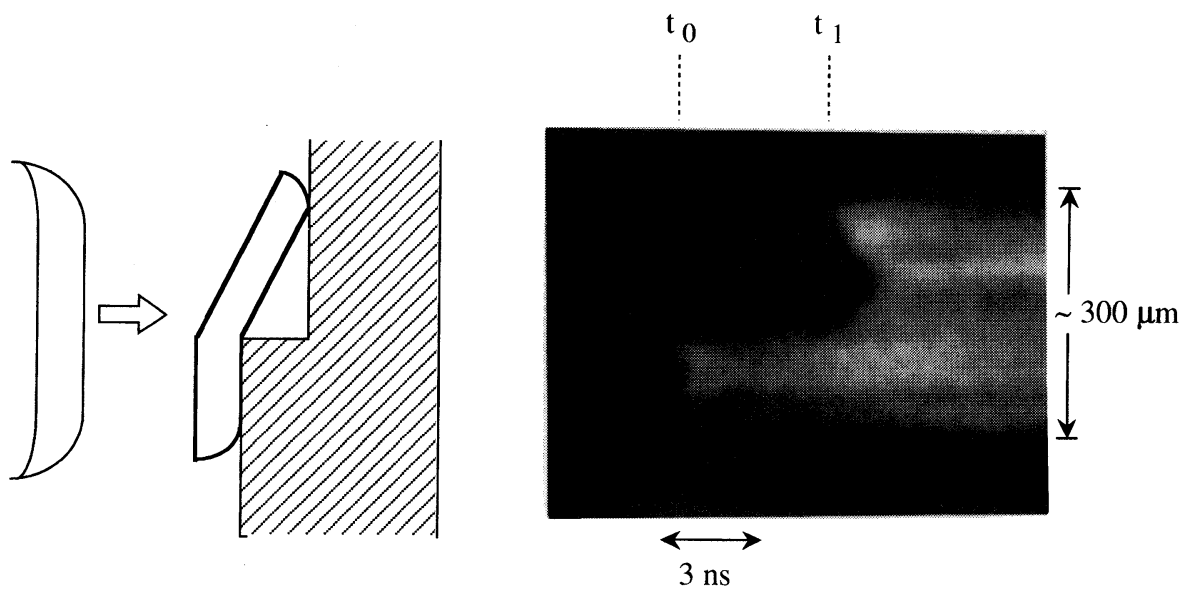

Fig.2 Laser accelerated $\mathrm{Al}$ flyer impacting on the step and a typical streak record observed in experiment. The step thickness was $150 \mu \mathrm{m}$.

Table 1 Velocity measurements of laser accelerated $\mathrm{Al}$ foil.

\begin{tabular}{cccc}
\hline \hline $\begin{array}{c}\text { Al thickness } \\
(\mu \mathrm{m})\end{array}$ & $\begin{array}{c}\text { Laser } \\
\text { energy }(\mathrm{J})\end{array}$ & $\begin{array}{c}\text { Intensity } \\
\left(\mathrm{W} / \mathrm{cm}^{2}\right)\end{array}$ & $\begin{array}{c}\text { Impact } \\
\text { velocity }(\mathrm{km} / \mathrm{s})\end{array}$ \\
\hline 18 & 15.9 & $4.0 \times 10^{13}$ & 35 \\
18 & 17.6 & $4.5 \times 10^{13}$ & 42 \\
25 & 25.9 & $6.6 \times 10^{13}$ & 25 \\
\hline \hline & \multicolumn{2}{c}{}
\end{tabular}

積もられている。

回収実験の場合の圧力の算出は, インピーダンスマッチ 法,および試料の $U_{\mathrm{s}}-u_{\mathrm{p}}$ 関係式を使って算出された。試料が $\mathrm{hBN}$ の場合には, 初期密度 $2.0 \mathrm{~g} / \mathrm{cm}^{3}$ で高圧相領域の関係式

$$
U_{\mathrm{s}}(\mathrm{km} / \mathrm{s})=1.0+1.95 u_{\mathrm{p}}(\mathrm{km} / \mathrm{s})^{10)}
$$

SiCの場合には初期密度 $2.5 \mathrm{~g} / \mathrm{cm}^{3}$ で

$$
U_{\mathrm{s}}(\mathrm{km} / \mathrm{s})=-0.2+2.8 u_{\mathrm{p}}(\mathrm{km} / \mathrm{s})^{11)}
$$

また白金に対しては密度 $21.4 \mathrm{~g} / \mathrm{cm}^{3}$,

$$
U_{\mathrm{s}}(\mathrm{km} / \mathrm{s})=3.68+1.46 u_{\mathrm{p}}(\mathrm{km} / \mathrm{s})^{10)}
$$

をそれぞれ使用した，実験後は, 回収試料を白金箔からは がして衝撃を受けた部分 (約直径 $1 \mathrm{~mm}$ )を採取し, 電顕観察 した. 回収実験の実験条件はTable 2にまとめられている.
Table 2 Experimental conditions of laser shock-recovered samples.

\begin{tabular}{cccccc}
\hline \hline Run \# & Sample & $\begin{array}{c}\text { Al flyer } \\
(\mu \mathrm{m})\end{array}$ & $\begin{array}{c}\text { Energy } \\
(\mathrm{J})\end{array}$ & $\begin{array}{c}\text { Flyer } \\
\text { velocity } \\
(\mathrm{km} / \mathrm{s})\end{array}$ & $\begin{array}{c}\text { Pressure } \\
(\mathrm{GPa})\end{array}$ \\
\hline 7R 3 & $\mathrm{hBN}$ & 25 & 4.4 & 4 & 11 \\
7R 1 & $\mathrm{hBN}$ & 18 & 5.1 & 9 & 53 \\
8R 5 & $\mathrm{hBN}$ & 18 & 16.1 & 33 & 640 \\
7R16 & $\alpha \mathrm{SiC}$ & 25 & 9.3 & 8 & 58 \\
7R15 & $\alpha \mathrm{SiC}$ & 18 & 13.8 & 28 & 670 \\
7R 8 & $\beta \mathrm{SiC}$ & 18 & 11.4 & 22 & 420 \\
\hline \hline
\end{tabular}

$\mathrm{hBN}$ では圧力 $11 \sim 640 \mathrm{GPa}, \mathrm{SiC}$ ばは 58〜 670GPaの圧力領域 で回収された。

Fig.3とFig.4はhBN回収試料のTEM像と電子線回折図が 示されている. 実験7R3で圧力 $11 \mathrm{GPa}$ の回収試料からは特 に変化は認められなかった７R1及び8R5の試料からは非 晶質物質が含まれていることが確認された。 また微細化 された粒子が生成していて,それらの電子回折図からは低 圧相のhBNであることが確認できた。しかし, hBNの高圧 相であるウルツ鉱型 $\mathrm{BN}(\mathrm{wBN})$ やジンクブレンド型 $\mathrm{BN}$ (cBN)の存在は確認できなかった。 また電顕観察中に不規 則な形をした試料部分は電子線を受けて形を変えたり発 泡したりする影響を受けるのが認められた。

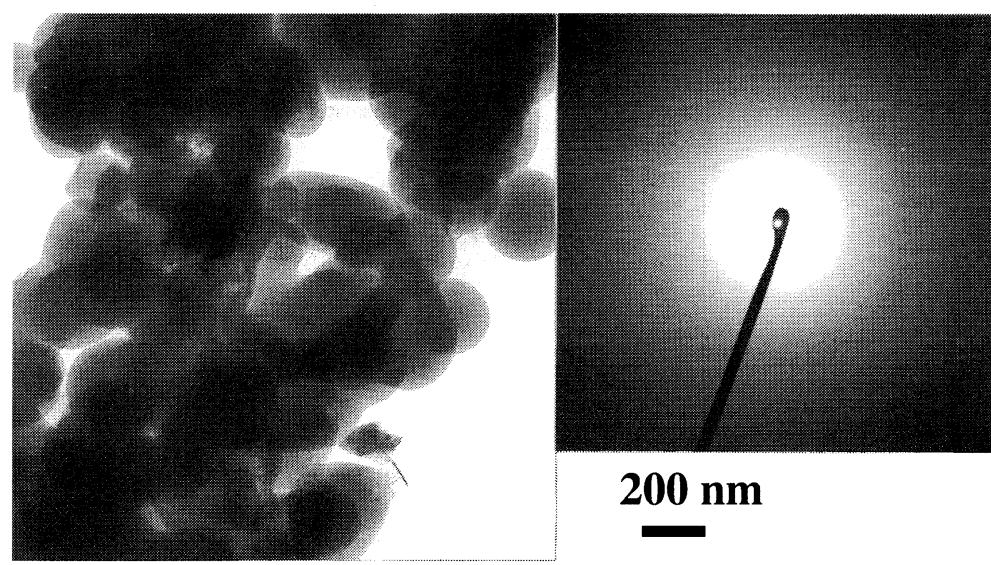

Fig.3 Microphotographs of run product \#7R1 showing amorphous spheres. Electron diffraction pattern is given at the right-hand side. 

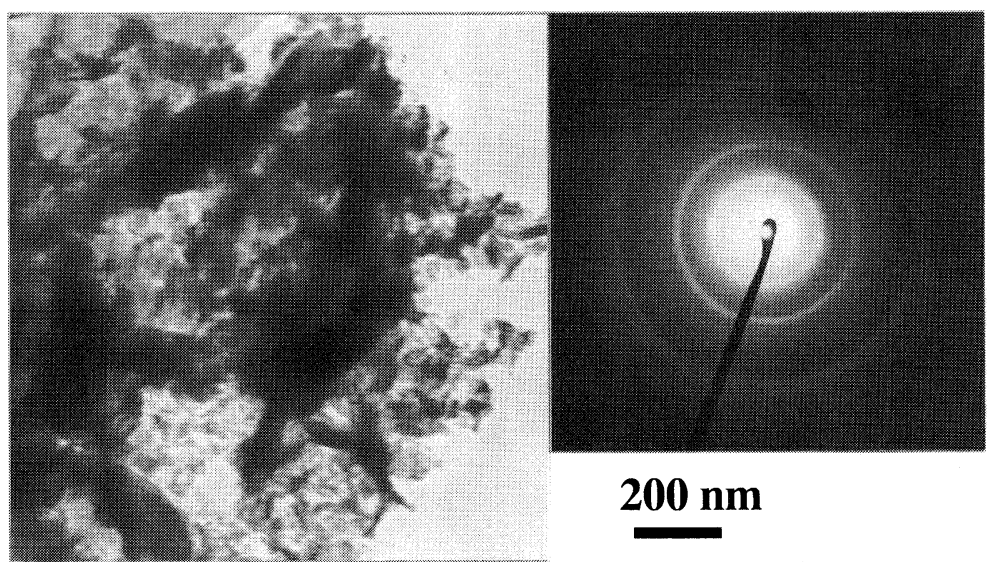

$200 \mathrm{~nm}$
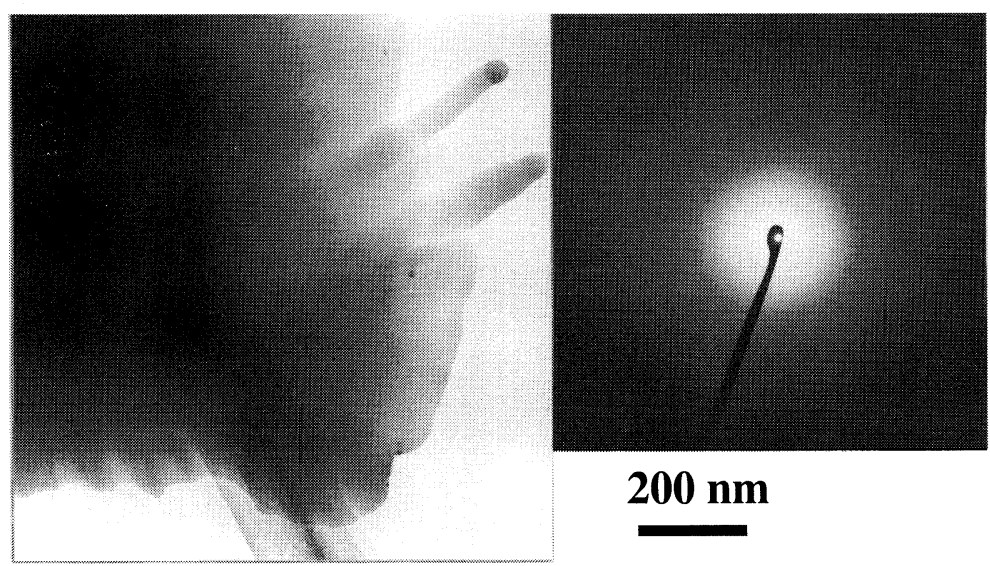

$200 \mathrm{~nm}$

Fig.4 Microphotographs of run product \#8R5 showing very fine particles of hBN (top) and amorphous grain (bottom). Each electron diffraction pattern is given at the right-hand side.

$\mathrm{SiC}$ 場合には, 最初の粒形がhBNに比べて1桁以上小さ く,粒子の微細化は認められなかった。また非晶質物質の 生成も確認できず,高圧結晶質相の生成も確認できなかっ た. 従って, SiCの回収試料は, 衝撃圧縮の効果を認める結 果は得られなかった。

\section{4. 考 察}

本実験では強力パルスレーザーにより加速されたAl微 小飛翔体の超高速衝突により衝撃波の発生および発生し た衝撃波の物質科学的研究の検討を行った. hBNと $\mathrm{SiC} に$ 対する衝撃波の効果を衝撃圧力 $11 \sim 670 \mathrm{GPa}$ で検討したが, いずれの回収試料中にも高圧相の生成は確認されなかっ た. hBNについては非晶質化と微細化が認められたが, $\mathrm{SiC}$ についてはそれらは観察されなかった。これらの実験結 果は, これまでの通常法による衝撃圧縮実験結果と比較す ることによって,レーザー衝撃波で物質科学的に何が出来 そうかに対して検討を加えるための基礎となるであろ j.

まずhBNについて考察する，通常の衝撃圧縮実験8)では， 数々の hBN試料に対してユゴニオ結果が既知であり, 約 10GPaを超えると高圧相転移が開始し, その高圧相は回収 試料の検討からwBNとして同定されている。 またcBNを 得るためには初期温度を高めたりくり返し衝撃圧縮する 必要がある。これらの実験結果と対比して考えると今回 のレーザー衝撃波実験では条件はシングルショックの状
態で試料厚みから考えて, 衝撃波の反射による繰り返し ショックは行われていないものと考えられる. 従って, 同 じピーク圧力で比較した場合に通常の衝撃圧縮実験に比 ベて, 試料はより高い衝撃温度を受けていると考えられ る. 例えば, 実験7R1に相当するピーク圧力の時では通常 の衝撃圧縮実験では回収試料中には70\%以上の $\mathrm{wBN}$ 同 定され, 非晶質物質は観察されない。また,このhBN-wBN 高圧相転移機構は, $\mathrm{hBN}$ 層間つまり $c$ 軸方向に圧縮を受け るとファンデルワールスカで結合していた原子間に新た な結合ができ高圧相へと転移する, 非拡散転移と考えられ ている. 従って, 速度論的には充分速く進行する. hBNwBN転移速度は, それぞれの結晶構造の相異から原子の動 きをみると黒鉛一ダイヤモンド転移より速いと考えられ， 黒鉛一ダイヤモンド相転移の場合にはユゴニオ測定からく $10 \mathrm{~ns}$ と実測されている12). しかしながら, 今回のレーザー 衝撃波の実験では高圧相が同定されなかったことから考 えると高圧相が急冷できなかったことになる，圧縮状態 でユゴニオ上に現れる高圧相が,そのまま凍結されるために は, 圧縮状態からの圧力解放過程で断熱膨張から高圧相が ブロックされ残存しなければならない.このブロックに は,生成した高圧相を成長させ安定化させるためのある程 度の時間がhBNの場合には必要だったのかも知れない.こ の点については通常の衝撃圧縮実験で圧縮時間を短くし てあるいはレーザー衝撃実験で圧縮時間を長くして検討 する必要がある.

hBNは黒鉛に構造的にも物理化学的性質においてもよく 
似ている．黑鉛の場合のレーザー衝撃波実験では, TPa領 域の回収実験から非晶質炭素が同定され, また発泡したダ イヤモンドが急冷された7)。この発泡ダイヤモンドの生成 は, 衝撃圧縮下で融解した単一原子から構成する液体炭素 から断熱澎張過程で生成したものと考えられる。このこ とはhBNの液体から高圧相が同様に生成するためには, 炭 素の場合程容易でないことを示している，2原子から構成 される液体BNからは,それぞれの原子が周期的な結晶格子 を組むのに，より長い時間が必要であるとして説明され る.この考察においては, BNの相図は炭素の相図にきわめ て類似していて, しかも平衡論的議論を前提としている. この前提は, 近い将来実験的に確認する必要があることは 言うまでもない.

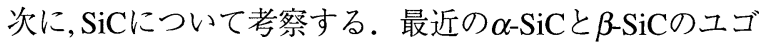
二オ測定からそれぞれ100〜120GPaで高圧相への転移が開 始し約140GPa以上では高圧相領域になることが明らかに なっている ${ }^{11)}$ 。通常の衝撃圧縮実験での100GPa以上での 回収試料からは, 高圧相の生成は認められていない13)。し かし, 高圧相については理論的考察14)やダイヤモンドアン ビルでの実験結果 ${ }^{15)}$ で低圧相と高圧相との観測された体 積差から配位数の増加を伴う $\mathrm{NaCl}$ 型であると提案されて いる、レーザー衝撃実験で回収されたSiCにおいては, hBN の場合に認められたような非晶質化や微細化などの衝撃 効果は認められなかった。これらのことからユゴニオ測 定で認められた衝撃誘起高圧相は, 可逆的で急冷困難であ ると考えられる。しかしながらこのSiCにおける高圧相転 移は, 含まれている炭素に注目すると, 低圧相ではダイヤ モンドと同等の4配位であるが高圧相が $\mathrm{NaCl}$ 型だとすると 6配位になり6配位炭素を有することになる．6配位炭素は， ダイヤモンドの高圧相として現在注目されている16).こ の6配位炭素は化学的にも物理的にもきわめて特異的な性 質を有するものと考えられ，その合成は挑戦的なものであ ろう．そのためには少なくとも TPa領域の圧力発生および 持続時間の長い圧縮法が必要となる。このような超高圧 力の発生には, MJオーダの強力レーザーの利用は必要なも のである。

\section{5. まとめと今後の展望}

高出カレーザーパルスの利用による微小飛翔体の加速, 超高速衝突による衝撃波の発生, 超高圧力の発生について 実験的研究を行った。またここのレーザー衝撃圧縮を受け た試料の解析を通して物質科学的検討を行った。その結
果, 通常の衝撃圧縮の結果とは異なることが明らかになっ た。これは衝撃圧縮時間が通常の衝撃圧縮時間の $10^{-3} \sim$ 10-2倍になっていることが大きく影響しているものと考え られる。

今後は, 加速された微小飛翔体の形状の平面性,つまり 発生する衝撃波の平面性を高め, 通常の衝撃圧縮実験の結 果と比較検討した上で, 発生圧力領域を高めてゆく必要が あり,更に精度の高い実験のためには基礎的デー夕の取得 が必要である。

\section{謝 辞}

本研究は, 阪大レーザー研での共同研究として実施され たものである. 本研究の費用の一部は, 科学技術振興調整 費総合研究「高密度パルス光の発生と先端的物質制御に関 する研究」から支援を受けた。

\section{参考文献}

1) C. G. M. van Kessel and R. Sigel: Phys. Rev. Lett. 33 (1974) 1020.

2) L. R. Veeser and J. C. Solem: Phys. Rev. Lett. 40 (1978) 1391.

3) R. J. Trainor, J. W. Shaner, J. M. Auerbach, and N. C. Holmes: Phys. Rev. Lett. 42 (1979) 1154.

4) R. Decoste, S. E. Bodner, B. H. Ripin, E. A. McLean, S. P. Obenschain, and C. M. Armstrong: Phys. Rev. Lett. 42 (1979) 1673.

5) R. Cauble, T. S. Perry, D. R. Back, K. S. Budil, B. A. Hammel, G. W. Collins, D. M. Gold, J. Dunn, P. Celliers, L. B. Da Silva, M. E. Foord, R. J. Wallace, R. E. Stewart, and N. C. Woolsey: Phys. Rev. Lett. 80 (1998) 1248.

6) G. W. Collins, L. B. Da Silva, P. Celliers, D. M. Gold, M. E. Foord, R. J. Wallace, A. Ng, S. V. Weber, K. S. Budil, and R. Cauble: Science 281 (1998) 1178.

7) T. Sekine, M. Yoshida, and K. A. Tanaka: in Advanced Materials'96 -New Trends in High Pressure Research- (NIRIM, Tsukuba, 1996) p.29.

8) T. Sekine, T. Kobayashi, and H. Nameki: J. Appl. Phys. 81 (1997) 527.

9) Y. Q. Zhu, T. Sekine, T. Kobayashi, and E. Takazawa: J. Mat. Sci. 33 (1998) 5883.

10) LASL Shock Hugoniot Data, ed. S. P. Marsh (Univ. of California Press, Berkeley, 1980) p.658.

11) T. Sekine and T. Kobayashi: Phys. Rev. B55 (1997) 8034 and in Shock Compression of Condensed Matter-1997 ed. S. C. Schmidt, D. P. Dandekar, and J. W. Forbes (AIP, Woodbury, 1998) p.141.

12) D. J. Erskine and W. J. Nellis: Nature 349 (1991) 317 and J. Appl. Phys. 71 (1992) 4882.

13）関根 利守: 未発表.

14) K. Karch and F. Bechstedt: Phys. Rev. B53 (1996) 13400.

15) M. Yoshida, A. Onodera, M. Ueno, K. Takemura, and O. Shimomura: Phys. Rev. B48 (1993) 10587.

16) T. Sekine: Appl. Phys. Lett. 74 (1999) 350. 